\title{
A Spectrophotometer implementation as project-based learning in Photonics Engineering
}

\section{Montaje de un espectrofotómetro como método de aprendizaje basado en proyecto de Ingeniería Fotónica}

\author{
Ó. Esteban 1,*, R. Vergaz ${ }^{2}$, X. Quintana ${ }^{3}$, M. Caño-García ${ }^{3,4}$ \\ 1. Departamento de Electrónica, Escuela Politécnica Superior, Universidad de Alcalá, Campus Universitario \\ $s / n$, Alcalá de Henares, Madrid. E28805 \\ 2. Departamento de Tecnología Electrónica, Escuela Politécnica Superior, Universidad Carlos III de Madrid, \\ Avda. Universidad 30, Leganés, Madrid, España. E28911 \\ 3. Departamento de Tecnología Fotónica y Bioingeniería, E.T.S. de Ingenieros de Telecomunicación, \\ Universidad Politécnica de Madrid, Avda. Complutense 30, Madrid. E28040 \\ 4. Department of Nanophotonics, Ultrafast Bio- and Nanophotonics Group, INL - International Iberian \\ Nanotechcnology Laboratory, Av. Mestre José Veiga s/n \\ 4715-330 Braga - Portugal \\ (*) E-mail: oscar.esteban@uah.es
}

Received: 17/05/2019 Accepted: 25/11/2019

DOI: $10.7149 /$ OPA.52.4.51022

\begin{abstract}
:
The construction of a low-cost spectrophotometer as part of project-based teaching for postgraduate students in the field of Photonics Engineering is depicted. The criteria followed in designing this project include considerations about budget, portability and multidisciplinary skills. The proposal has been carried out in the context of a 3 credit Experimental Projects I course, part of the Master in Photonics Engineering taught by the Polytechnic University of Madrid, University Carlos III of Madrid and University of Alcala. During its performance, students have been supplied with all the necessary mechanical and optomechanical hardware, as well as passive and active optical elements and driving circuitry. Their tasks include the manufacture of a diffraction grating by a brand-new nanoimprint technique, the optimization of the optical alignment for improving the optical transfer function and the signal-to-noise ratio at the detection stage, and the programming of the control system and data acquisition in a LabView environment. The outcome is a fully functional spectrophotometer.

Although it has been designed and tested with students of photonics, its multidisciplinary and modular character makes it useful also for undergraduate students from different disciplines, such as Industrial, Electronics or Automation Engineering. The open availability of the mechanical and electronic designs further allows its use by secondary teachers as a demonstrator of the different concepts used in their implementation (photonics, mechanics, electronics and software).
\end{abstract}

Key words: Photonics Engineering, spectrophotometer, project-based learning, low-cost

\section{RESUMEN:}

Se describe la construcción de un espectrofotómetro de bajo coste como parte de la enseñanza basada en proyectos para estudiantes de postgrado en el campo de la Ingeniería Fotónica. Los criterios seguidos en el diseño de este proyecto incluyen consideraciones sobre el presupuesto, la portabilidad y las habilidades multidisciplinarias. La propuesta se ha realizado en el marco de un curso de Proyectos Experimentales I de 3 créditos, enmarcado dentro del Máster en Ingeniería Fotónica impartido por la Universidad Politécnica de Madrid, la Universidad Carlos III de Madrid y la Universidad de Alcalá. Durante su ejecución, los alumnos han recibido todo el hardware mecánico y optomecánico necesario, así como elementos ópticos pasivos y activos y circuitería de accionamiento. Sus tareas incluyen la fabricación de una red de difracción mediante una nueva técnica de nanoimpresión, la optimización 
del alineamiento para mejorar la función de transferencia óptica y la relación señal/ruido en la fase de detección, y la programación del sistema de control y la adquisición de datos en un entorno LabView. El resultado es un espectrofotómetro totalmente funcional.

Aunque se ha diseñado y probado con estudiantes de fotónica, su carácter multidisciplinar y modular hace que sea útil también para estudiantes de grado de diferentes disciplinas, tales como Ingeniería Industrial, Electrónica o en Automatización. La disponibilidad abierta de los diseños realizados, permiten adicionalmente su uso por parte de profesores de secundaria como demostrador de los diferentes conceptos utilizados en su realización (fotónicos, mecánicos, electrónicos y software).

Palabras clave: Ingeniería fotónica, espectrofotómetro, aprendizaje basado en proyecto, bajo coste

\section{REFERENCES AND LINKS / REFERENCIAS Y ENLACES}

[1] T. Scharf, "Optical engineering: Understanding optical system by experiments", in 14th Conference on Education and Training in Optics and Photonics, ETOP 2017 Proc. X. Liu and X. Zhang, eds., SPIE Proc. 10452, 104521-F (2017)

[2] W. Johnstone, B. Culshaw, D. Walsh, D. Moodie, I. Mauchline, "Student Laboratory Experiments on Erbium Doped Fiber Amplifiers and Lasers", in 6th Conference on Education and Training in Optics and Photonics, SPIE Proc. 3831, 259-267 (2000)

[3] A. Pérez Camacho, A. Janowski, A. Konak, S. Kulturel-Konak, “Creative Problem-Solving Builds Entrepreneurial Mindset”, in Proc. of the 6th IEEE Integrated STEM Education Conference, 65-70 (2016)

[4] N.M. Massa, M. Dischino, J. Donnelly, F. Hanes, "Problem-Based Learning in Photonics Technology Education", in Novel Optical Systems Design and Optimization XI, Proc. SPIE 7061, 70610S (2008)

[5] A.F. Zhou, "Integrating Undergraduate Research into the Electro-Optics and Laser Engineering Technology Program at Indiana University of Pennsylvania”, in 12th Conference on Education and Training in Optics and Photonics, ETOP 2013 Proceedings, M. Costa and M. Zghal, eds., SPIE Proc 9289, 92890K (2014)

[6] J.R. Savery, "Overview of Problem-based Learning: Definitions and Distinctions", Interdisciplinary Journal of Problem-Based Learning 1, 9-20 (2006)

[7] F.L. Naranjo, G. Martínez, Á.L. Pérez, P.J. Pardo, "Design, development, testing and validation of a photonics virtual laboratory for the study of LEDs", in 12th Conference on Education and Training in Optics and Photonics, ETOP 2013 Proceedings, M. Costa and M. Zghal, eds., SPIE Proc 9289, 92891T (2014)

[8] https://aplicaciones.uc3m.es/cpa/generaFicha?est=338\&asig=17362\&idioma=2

[9] R.F. Selfridge, S.M. Schultz, A.R. Hawkins, "Free-space optical link as a model undergraduate design project", IEEE Transactions on Education 50, 208-215 (2007)

[10] Lin Zhili, Li Xiaoyan, Zhu Daqing, Pu Jixiong, "MATLAB-aided teaching and learning in optics and photonics using the methods of computational Photonics", in 14th Conference on Education and Training in Optics and Photonics, ETOP 2017 Proc. X. Liu and X. Zhang, eds., SPIE Proc. 10452, 104521W (2017)

[11] D. Kokotsaki, V. Menzies, A. Wiggins, "Project-based learning: a review of the literature", Improving schools 19, 267-277 (2016)

[12] https://github.com/albireo1972/Low-cost-spectrometer

[13] https://omronfs.omron.com/en_US/ecb/products/pdf/en-ee_sx3070_4070.pdf

[14] www.lumileds.com

[15] https://ams.com/

[16] www.analog.com/en/index.html\#

[17] M. Caño-García, M.A. Geday, M. Gil-Valverde, A. Megías-Zarco, J.M. Otón, X. Quintana, “A 3D printed device for polymer nanoimprint lithography”, Review of Scientific Instruments 89, 025106 (2018)

[17] https://www.labviewmakerhub.com/doku.php?id=libraries:linx:start 


\section{Introduction}

The education of professionals in the field of science and engineering requires paying special attention to the ability of students to formulate and deal with complex problems, both theoretically and practically [1 3]. In general, it is usual to find practice programs in the different subjects that make up a curriculum, although their scope is usually limited to the contents of the subject itself, either due to temporal limitations, to constrained teaching resources or to the lack of synergy between the different subjects. However, after this formative period, students will to have to face complex multidisciplinary problems in their future career, in which they will have to apply all the set of competences and skills acquire during their training period, as well as their previous experience in the field of research, development or management $[1,4]$.

With the aim of providing students with an integral education enabling them to approach this kind of problems since their professional beginnings, new teaching techniques based on learning through the resolution of complex problems have been developed [4]. In this new paradigm, students must look for the practical solution of a specific problem, for which they must use their theoretical knowledge about the phenomena underlying the problem, whilst they must find technological solutions to the specific application they face. The fundamental idea of this paradigm is to endow the student with a certain autonomy when it comes to focusing on the solution of the problem, fostering both his/her technical/technological ability and critical thinking in the interpretation of the obtained results [5,6].

When posing a practical problem, different points must be considered, mainly regarding the scope of the problem as well as the practical limitations that usually occur in the field of higher education. In the specific case of photonics, these limitations are usually associated with the high cost of the equipment and its availability, even for a small number of students [1]. Further constraints are the temporary restrictions on access to such equipment and the closed nature of the instrumentation, which reduces the improvement options and the number of tests that can be carried out by students [7].

In this work, a teaching proposal consisting on the realization of a photonics engineering project based on the design, manufacturing, control and data extraction of a low-cost spectrophotometer as an end-product is described. The aim of this problem is primarily, but not exclusively, to complete the abilities associated with the Interuniversity Master's program in Photonics Engineering taught by the Polytechnic University of Madrid (UPM), University Carlos III of Madrid (UC3M) and University of Alcala (UAH) in the subject of Experimental Projects I [8]. It is also an objective to reinforce and integrate the theoretical and practical knowledge acquired in the whole program of the Master.

\section{Project design criteria}

In designing the problem to be solved, practical considerations have been taken into account, as well as the interest in a proposal being multidisciplinary enough so as to, in small work groups, each student take responsibility for part of the project without forgetting the interaction with the other group members to get a successful outcome. Furthermore, the project should enhance the development of the skills and competencies acquired in a photonics program, i.e., in the use and optimization of light emitters and detectors, applications of non-guided radiation or the use of software tools for both instrument control and data acquisition and treatment.

Specifically, the initial requirements for this proposal have been the ones listed below [9]:

1. Low cost of the whole project. Not only because of the budgetary limitations inherent in the current performance of higher education [10], but also with the ulterior objective of being able to extend the range of application beyond master's students. For instance, to either on-line [1,7] or undergraduate courses, and even high school teaching. In this way, with a relatively accessible equipment, any student could be able to complete the project by his/her own means.

2. Portable. With this requirement it is possible for them to carry out a continuous work, not being constrained by the availability of facilities and/or teaching staff. This concept also contributes to the reinforcement of collaborative work and allows sharing ideas and solutions with other groups addressing the same problem $[1,3,4,11]$.

3. Visual. The hardware used for the construction of the spectrophotometer are mostly discrete. In this way, students can follow the entire process of spectral interrogation of light, from the emission to the detection stages. Moreover, the students can observe the radiometric and wave 
effects involved in the operation of the instrument. This is intended to illustrate the conditioning factors they may encounter during their future work, such as the dimensioning of unguided links, the effect of background radiation, the use of passive elements to improve the optical transfer function, etc.

4. Multidisciplinary. The proposal is not restricted to the constrained scope of photonics, since it includes aspects of mechanical design and manufacturing (all optomechanical elements of positioning and alignment), design and implementation of electronic circuits (LED driver, photodiode biasing and signal amplification, use of optoswitches), electronic control (step-bystep motor control, use of microcontrollers, Arduino integration) and development of software applications based on LabView (integrated control of the various active components, acquisition and processing of data). Thus, it contains hands-on mechanics, 3D printing, electronics, control, and their related software.

5. Scope. Following the idea of a multidisciplinary lab, our proposal carries such a didactical content that it could be extended to a wide range of possible audiences beyond Photonics Engineering. The setting up of the instrument could be performed by any student in Mechanics Engineering, to show it a possible scientific application of a simple motors-and-gears arrangement. Or to any student of Industrial Engineering, not only in Electronics or Automation, to show the application of the components that they use in a scientific instrument made by their own. Even more, it could be proposed as a horizontal practice, in which one student of each Grade could take part of a multidisciplinary transversal lab Group to come up with her/his own ideas and know-how to build the whole instrument. And, with a proper guidance, it could be also a step-by-step workshop for advanced high school students of Science.

6. Open-end concept. Given the assembly nature, the system is open to the incorporation of new elements or designs by the students, provided that the final proposed objective is achieved. To this end, students are encouraged to integrate their own solutions, with the teacher's guidance in the analysis of their feasibility and to obtain the possible different additional hardware elements required by the new design.

\section{Practical implementation}

From the criterion 4 outlined above, it is easy to see that the project contains several working areas so that the application can be modular. Thus, the proposed project can be adapted to the previous acquired skills of the students and even to the composition of the working groups. A schematic draw of the proposed spectrophotometer is plotted in Fig. 1, where all the basic elements are presented. These include photonic, mechanical and electronic components and devices, which are all biased and/or controlled through an Arduino device.

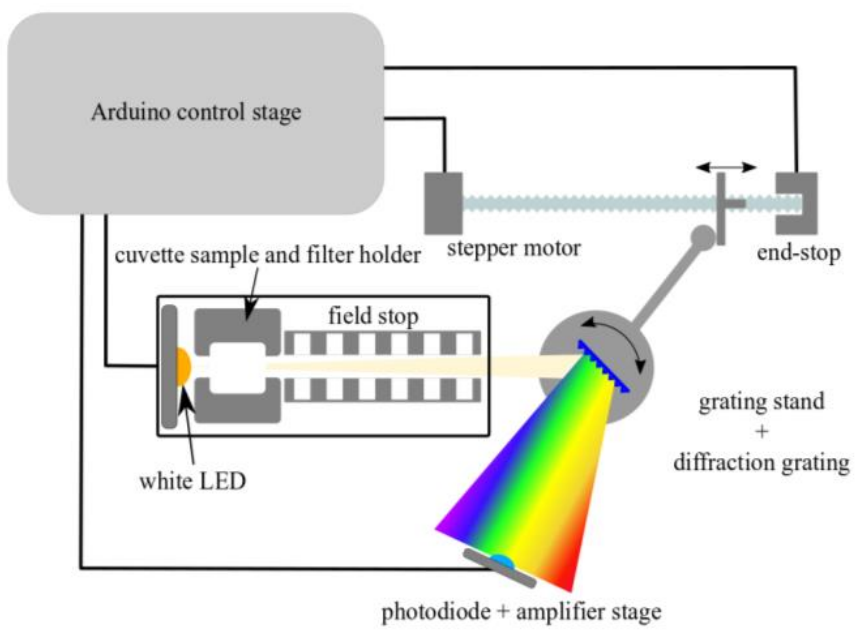

Fig. 1. Schematic draw of the proposed spectrophotometer. An Arduino stage drives all the mechanical and electrical subsystem s and records the data of the measured spectrum for further analysis.

This scheme is presented to the students through an introductory session of about one hour in which the work to be developed is exposed to them. The released information includes the theoretical basis of the 
instrument to be built, the objectives to be achieved, the initial supplied material and the evaluation criteria. All the contents of this first session are collected in a handbook which also provides a guide about the expected results, and a set of milestones that students must verify during their development and that will be evaluated by the staff to propose the final mark.

\section{3.a Supplied hardware}

The basic material supplied to the students in the first session includes the different optomechanical elements necessary to fix and align the different devices that comprise the spectrophotometer. In order to accomplish with the criterion of being low cost, these elements have been manufactured using plastic 3D printing. All the mechanical hardware has been intentionally designed to be manufactured with large tolerances. This feature contributes to put the spot on the importance of the correct alignment of the several optical components for getting an optimized optical transfer function and thus a high signal-to-noise ratio in the recorded signal. An example of this kind of hardware appear in the Fig. 2, where the different supplied parts are shown. As can be seen, this set includes a $22 \times 22 \mathrm{~cm}$ perforated plate with M4 metric holes in which the various components can be fixed. These basic built-in components are:

- The diffraction grating stand and the bearings for enabling its rotation.

- A holder that allows the placement of the PCB-LED, a cuvette sample and a filter. This part also includes field-stop buffers to reduce the stray light impinging the diffraction grating. Students must place a $0.5 \mathrm{~mm}$ width slit at its end.

- A piece to place the photodiode PCB board, which allows its vertical alignment.

- A holder for the opto-interrupter end stop.

- A set of pieces for locking and adjusting the different elements on the perforated board.

All these pieces are available to be downloaded on line at [12]. Together with this all mechanical stuff, a set of simple watchmaker's lenses with different focal lengths and a power supply adapter are also supplied.

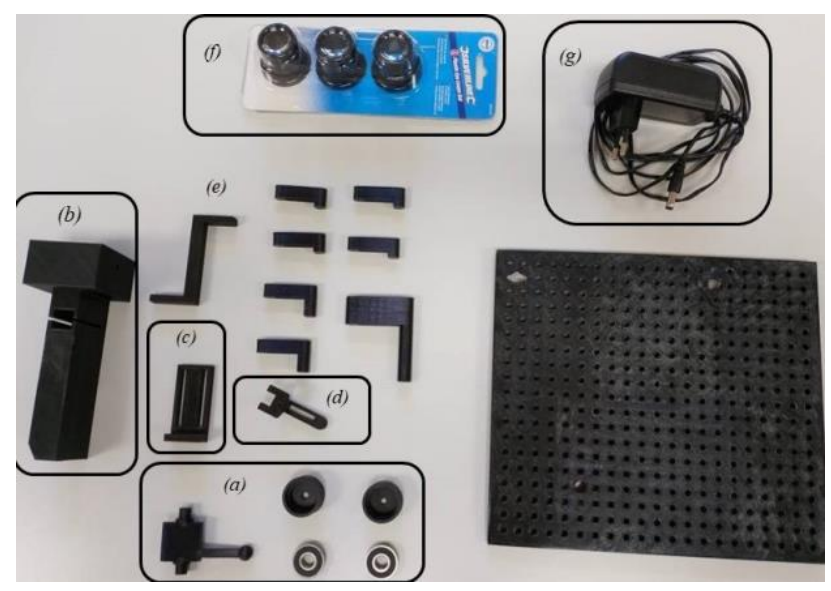

Fig. 2. Optomechanical elements supplied. A perforated plate is included in which the various components are fixed: (a) diffraction grating stand and the bearings that allow its rotation, (b) holder of the PCB-LED, a cuvette sample and a filter, (c) base of the photodiode PCB board, (d) holder of the opto-interrupter, (e) pieces for locking and adjusting the different elements on the perforated board, (f) lenses with different focal lengths and (g) power supply source $12 \mathrm{~V} / 1.25 \mathrm{~A}$

Alongside these optomechanical elements, the necessary active devices are also provided with its control electronics. This set of subsystems is shown in Fig. 3. They consist of a 5V, 2-phase and 4-wire Origlam stepper motor. This motor is placed in a setup that contains an endless screw that linearly displace a piece back and forth. This piece is attached to a rod that connects the motor to the diffraction grating stand. The driver for this motor is a Pololu's DRV8834, which generates the necessary current to activate the motor in each step. This is a simple interface to generate the activation pulses to the four wires of the motor. This motor can operate with a full step, but also with either $1 / 2,1 / 4$ or $1 / 8$ step, and an Omron EE-SX3070/SX4070 transmissive opto-interrupter [13] will act as end stop at the end of the motor screw length. 
A white LED LXR7-xW57 [14], powered at 12V is used as light source, with the forward current limited through a series resistance in the range of tens of ohms. This LED renders a color temperature of $5700 \mathrm{~K}$ and has local emission maxima at $450 \mathrm{~nm}$ and $580 \mathrm{~nm}$ respectively. The spectral location of these maxima will be used to calibrate the spectral performance of the final instrument. At the detection stage, a TSL257 [15] photodiode is provided. This Photodiode integrates a stabilized transimpedance preamplifier with a responsivity of $1.58 \mathrm{~V} /(\mathrm{W} / \mathrm{cm} 2)$ at $565 \mathrm{~nm}$. Eventually, this system may require an additional gain, which has been implemented on a PCB with a LT1006 [16] operational amplifier in non-inverting configuration.

All these active devices, namely step-by-step motor, opto-interrupter, LED and photodetector, are both controlled and biased through a shield for Arduino UNO specially designed and implemented by us, so that a single integrated electronics board allows the management of the complete system. The PCB designs are also available on line at [12]. The overall budget of these components, including both mechanical and electronics, is kept below $100 €$ for each spectrophotometer.
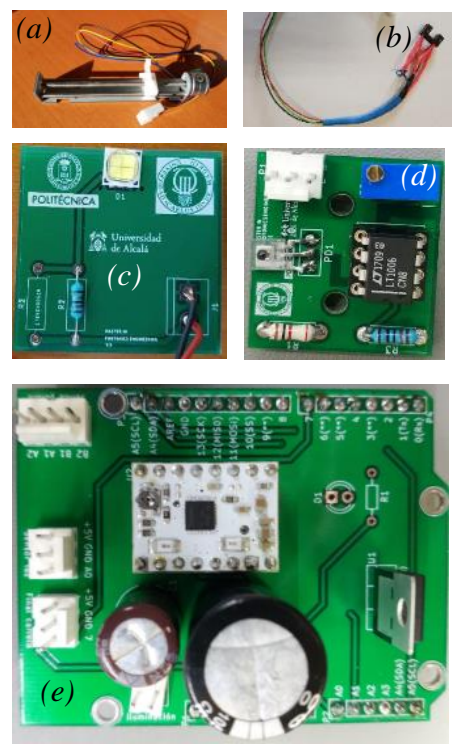

Fig. 3. Supplied mechanical, optoelectronic and electronic subsystems. (a) Linear step-by-step motor, (b) end stop, (c) white LED, (d) photodiode with additional transimpedance amplifier and (e) connection shield with Arduino UNO.

\section{3.b Components to be manufactured by students}

To get a functional spectrophotometer, it is essential to have a dispersive element, which can be either a prism or a diffraction grating. When using a diffraction grating, its performance follows the equation (1)

$$
\sin \theta_{m}=m N \lambda \text {, }
$$

where $\theta_{m}$ is the angle at which a maximum is obtained, $m$ is an integer representing the diffraction order, $\mathrm{N}$ the number of lines per mm of the grating and $\lambda$ the diffracted wavelength. Thus, the angular dispersion can be written as

$$
\frac{\mathrm{d} \theta}{\mathrm{d} \lambda}=\frac{m N}{\cos \theta},
$$

where the product $R=m \cdot N$ is known as the Resolvance of the diffraction grating, which increases with $N$ for a fixed diffraction order $m$.

In our proposal, the selected dispersive element is a diffraction grating with 1800 lines $/ \mathrm{mm}$. Although there are several means of getting an useful diffraction grating for the students by its own means, for instance from a bare section of either a CD (625 lin/mm), a DVD (1351 lin/mm) or a Blu-ray (3125 lin/mm), we have taken advantage of the expertise and facilities in the UPM and its clean room (a class 10.000 one) to put them in contact with a technological environment. Thus, the students manufacture and characterize their own grating during the first practical work session. The fabrication method is based on a nanoimprint technique, while the characterization is performed though AFM techniques. 
In regard to the grating, a copy from a master structure previously available in the laboratory (Thorlabs GR13-1850) is done. This master is made of silicone (Corning Sylgard-184), while the copy will be made on the UV-cured adhesive NOA 81. This adhesive is spin-coated on a clean glass slide cover previously treated in an ozone-atmosphere oven for $10 \mathrm{~min}$. Thus, a thin adhesive layer is deposited after spinning a drop during 5 seconds at $1000 \mathrm{rpm}$ and a further spinning speed to $2500 \mathrm{rpm}$ for another 30 seconds. Once this substrate is done, it is placed over the silicone master copy in the replicator, where a pressure of $100 \mathrm{mbar}$ is applied while the adhesive hardens under UV radiation for $2 \mathrm{~min}$ [17]. Finally, the grating is metallized with a thin layer of aluminium $150 \AA$ thick in an electron gun deposition equipment. After finishing this process, a grating like the depicted in Fig. 4 is obtained and the students already have all the necessary components to make their own spectrophotometer up.

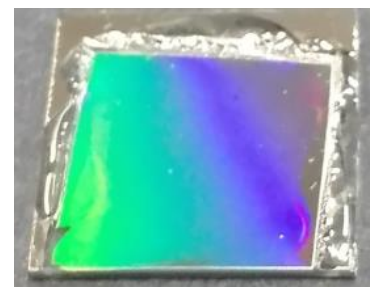

Fig. 4. Picture of the manufactured diffraction grating

\section{Making up a spectrophotometer}

With all the components available, the next step is to arrange all of them to get a functional spectrophotometer. The first activity is to install and verify the communications between Arduino and LabView. Installing Labview's Linx plugin in the PC allows an easy connection of both systems by using their built-in VIS [18]. Once installed, the communications are verified by the students through the activation of the stepper motor and the detection of ambient light from the photodetector setup. In this point, the adjustment of the transimpedance amplifier gain is done to prevent detector saturation.

After this, the correct alignment of the different devices on the perforated plate is the main task. Further passive optical devices can be used in this stage to improve the signal-to-noise ratio on the photodetector. Once all the optical components are pre-aligned, with a preliminary visual inspection following the design criterium 3, both the control and data acquisition and plotting routines are setting up. The rest of the work is to further optimize the spectrophotometer performance (both optical alignment and control routines) in an iterative process.
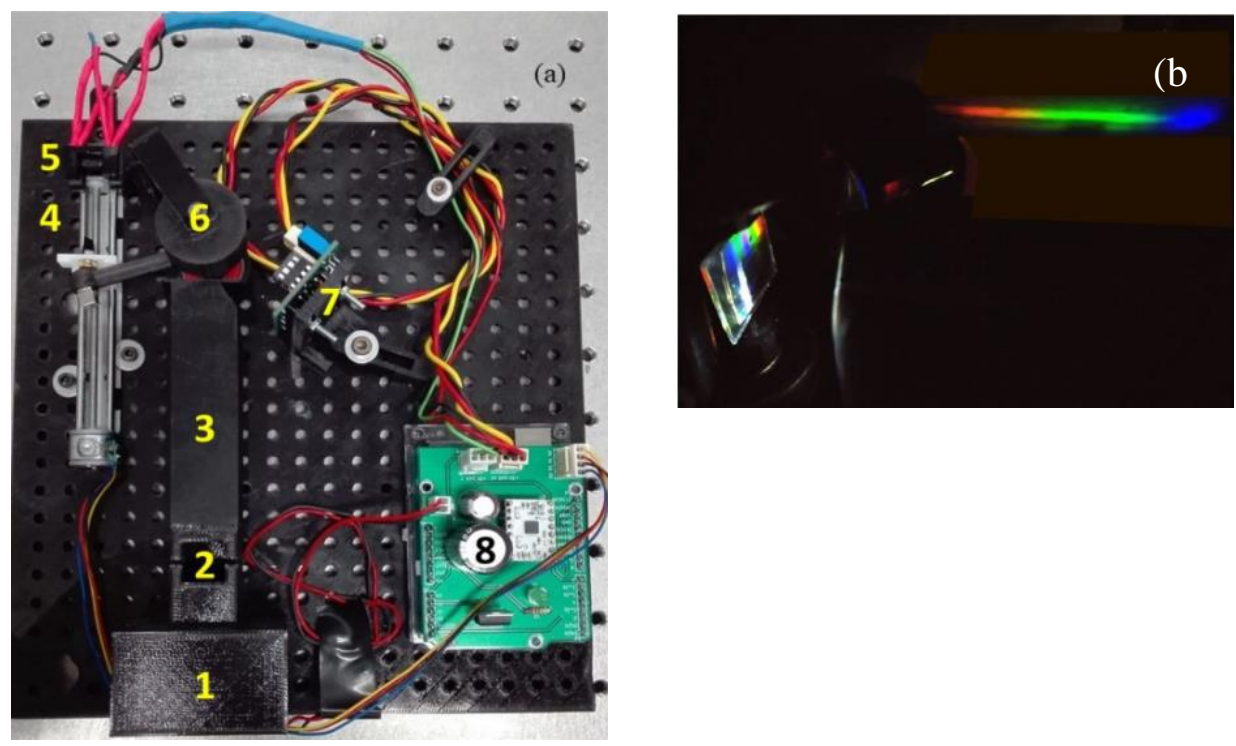

Fig. 5. (a) Top view of the complete spectrophotometer: 1. LED holder, 2. Sample cuvette and filter holder, 3. Field stop, 4. Step-bystep motor, 5. Optointerrupter end-stop, 6. Diffraction grating stand, 7. Photodiode and amplifier stage and 8. Shield and Arduino control platform. (b) Visible spectrum obtained with the $1800 \mathrm{lin} / \mathrm{mm}$ fabricated grating. 
An example of the implemented spectrophotometer is shown in Fig. 5a where a top view of the arrangement with all the implemented subsystems can be seen, while a view of the spectral dispersion is plotted in Fig. $5 b$.

Once spectrophotometer is implemented and all the components are optically aligned, the phase devoted to the control and data acquisition through LabView tool begins. At this point, the students must focus on:

- the accurate timing to move a step in the motor and read the photodiode voltage level,

- the caring of not having a photodiode circuit saturation in any part of the motor sweep,

- the recording and plotting of an array in which every voltage level is loaded, and

- the mathematical operations to calculate the absorptance and transmittance of the sample using the LED reference spectrum.

In the setup shown in Fig. 5a, the diffractive grating rotates from left to right. This means that the photodetector records the long wavelength irradiance first and the spectrum would appear as inverted, with the red part at the left side and the blue one at the right side. To represent the recorded spectrum in the usual way, that is, increasing wavelength from left to right, a data inversion is set in the developed software.

This software includes a preliminary measurement of the light source spectrum to take a reference, followed by the capture of the spectral transmission through the sample. With both measurements, a single calculation renders either the absorptance, transmittance, etc.

An example of the front screen developed is shown in Fig. 6. In this capture, four plots are presented. From left to right and from top to bottom: the recorded LED spectrum, the measured spectral transmission when a green filter is located between the LED and the grating, the transmittance percentage through the filter and the filter absorptance.

A further utility that the students must implement in this software, is the data export, as would be feasible in a commercial spectrometer. This utility allows to record data as a table for its further analysis.

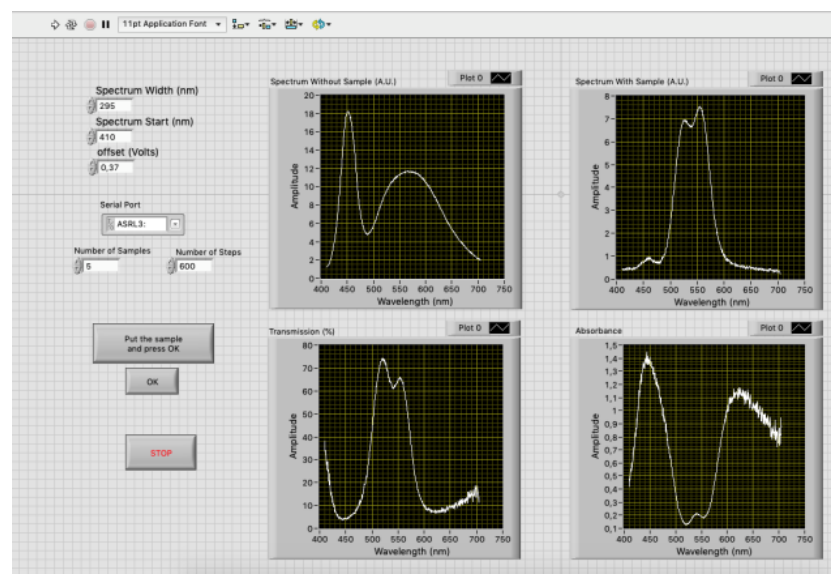

Fig. 6. Front panel of the LabView-based developed software. From left to right and from top to bottom, the LED recorded spectrum (top left), the spectral transmission through a green filter (top right), the filter transmittance percentage (bottom left) a nd the filter absorptance (bottom right) are plotted.

\section{Some results}

To validate the spectrophotometer performance, it must be previously wavelength calibrated. For this purpose, the local maxima of the used LED provided by the supplier are used. In our case, as said above, these maxima are located at both $450 \mathrm{~nm}$ and $580 \mathrm{~nm}$ respectively. With these values, it is possible to correlate each motor position with the wavelength. After doing so, the spectrophotometer is ready to be used as a fully operative instrument. 
The spectrophotometer has been proved to work in the range $400-750 \mathrm{~nm}$, with a scanning speed that will depend on the desired resolution. This resolution is defined by the step of the motor, which have impact in the angle step between consecutive incidence angles on the diffraction grating. Thus, the instrument resolution can be roughly assessed through the ratio between the whole spectral range and the number of steps used to get such spectrum (3)

$$
\delta \lambda=\frac{\Delta \lambda}{n},
$$

where $n$ is the number of steps done. Thus, with around 650 steps, which has been a usual number tested, the resolution is of about $0.6 \mathrm{~nm}$. Obviously, such steps number will also play a role in the time needed to get the spectrum. As a significant figure, the maximum spectral resolution takes around $50 \mathrm{~s}$ to be completed.

After calibrating, the students use their spectrophotometer for further experiments proposed by themselves, in which spectral interrogation is the key point. Some of the proposed experiments include spectral absorptance and transmittance of filters and liquids, fluorescence measurements in which a new local maximum is appreciated after irradiating the sample with the light source, verification of the BeerLambert law, etc.
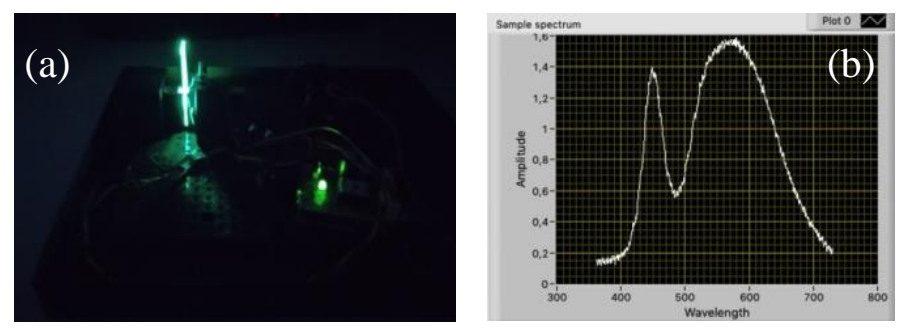

Fig 7. (a) Picture of the spectrophotometer with a fluorescent glass slide as sample. (b) Transmission spectrum of the fluore scent sample

An example of such performance is depicted in Fig. 7. In this figure, a picture of the spectrophotometer with a yellow fluorescent glass slide appears in Fig. 7a, while the transmission spectrum is plotted in Fig. 7b. As can be seen, in this later case, the yellow part of the spectrum, centered around $555 \mathrm{~nm}$, increases over the value obtained when measuring the LED source spectrum (see Fig. 6 top left). This is the expected result for a fluorescent sample, in which high energy radiation is absorbed and utterly re-emitted at a lower one.

\section{Learning evaluation}

Each step of the depicted above, can be considered as a milestone of the learning process. These milestones can be summarized as:

1. Manufacturing and characterization of the diffraction grating.

2. Installation and verification of communication between Arduino UNO and LabView. Checking of motor displacement and environmental light detection with the photodetector.

3. Setting up of the optomechanical components and passive optical devices (collimation/focusing lenses, diffraction grating, slit, etc.). Optical alignment.

4. Preliminary tests work. Data storage and plots.

5. Spectrophotometer calibration with the LED local maxima.

6. Spectral transmittance/absorbance measurements with filters and liquid samples.

7. Implementation of proposed improvements over the basic instrument. Final validation of performance.

As already said, each milestone is assessed by the staff during the regular sessions fixed in the course schedule. But also a final session is used to show the final performance of the implemented spectrophotometers by each teamwork. In this session, a short presentation is required, in which students summarize the whole process followed to setting up their project, the obtained results and their 
relationship with the photonic phenomena involved, the difficulties found and the adopted solutions, as well as their satisfaction/complaints with both the results and the course content. They also perform a demo of their instrument. After this short presentation, both the rest of students and staff can add their own comments over the performance of the instrument, the adopted solutions and the results interpretation in a fruitful and constructive discussion. Thus, the students work is assessed by teachers as well as by peers.

The final mark is the outcome of the spectrophotometer functionality, the appraisement of the presentation and the assessment of a final written report, which can be supported by the multimedia presentation itself, collecting all the developed work. In this report, all the steps done for implementing the spectrophotometer, its basic features (sensitivity, spectral resolution, repeatability, etc.), and the measurements done must appear.

After completing this entire hands-on learning program, students have demonstrated their ability to develop a laboratory instrument of their own, have acquired skills in handling optical and electronic instruments and in performing precise photonic assembly, but more importantly, have understood the multitude of variables that can induce measurement errors, and how to minimize them.

Some of the comments collected during the presentations emphasize that, in their own words, "this is the best way to learn how a system works, to understand the difficulties that appear when assembling it and to undertake them. The theoretical concepts on which the instrument is based, go from being merely equations without a clear meaning to something physically tangible. Splitting the work and structuring it to execute it efficiently has led us to make true engineering".

\section{Conclusion}

A project-based learning has been designed and implemented in the Experimental Projects I course, within a Photonics Engineering master's degree, although its scope can go beyond this implementation to be deployed in several undergraduate courses and even as demonstrator for high school students. The designed project implies the assembly and putting into operation of a low-cost spectrophotometer, fully operative as lab instrument. This approach demonstrates that students can acquire and reinforce concepts much more effectively than in a traditional format, and a fast learning curve with the minimum number of credits used is got.

These concepts include some basics of optics and photonics, but also skills such as handling optical and optoelectronic instruments, optical assembly and alignment, the use of hardware and software tools that will be useful in their future careers, etc. All this using a portable system that they can develop in a selfregulated time management. Furthermore, the project has been designed to be of a very low cost in general, which paves the way to be released also in on-line courses. In our case, an exception has been adopted. The manufacturing of a specific diffraction grating has allowed to put the students into contact with advanced instrumentation on a professional environment such a clean room is.

Although the proposal has been designed to be used in a Photonics Engineering degree, and therefore the optomechanical and electronic components have been supplied from the beginning, the modular character of the system enables to release some parts of the system more or less developed to the students, depending on their previous knowledge and expertise. Thus, if the system is intended to be used with trained students in electronics engineering, the design and development of the control of the system, including both the movement of the motor and the activation/interrogation of the different active devices that compose it, could be part of their own work.

\section{Acknowledgements}

This work has been partially supported by Spanish Economy and Competitiveness Ministry (AEI/FEDER funds, UE) through projects TEC2016-77242-C3-1-R and TEC2016-77242-C3-2-R, and by the Comunidad de Madrid programs SINFOTON-CM (S2013/MIT-2790) and SINFOTON2-CM (P2018/NMT- 4326).

The authors also wish to thank Mr. Armando Muñoz and Mr. Ricardo Hervás for his contributions to the mechanics and electronics of the project, and to our students Clara Quevedo, Gabriel Cano and Raúl Nieto for kindly giving up their results for Fig. 7. 